\title{
Effect of cardiac ventricular mechanical contraction on the characteristics of the ECG: A simulation study
}

\author{
Ismail Adeniran $^{1}$, Jules C. Hancox ${ }^{2}$, Henggui Zhang ${ }^{1,3^{*}}$ \\ ${ }^{1}$ School of Physics and Astronomy, The University of Manchester, Manchester, United Kingdom \\ ${ }^{2}$ Department of Physiology and Cardiovascular Laboratories, School of Medical Sciences, Bristol, United Kingdom \\ ${ }^{3}$ School of Computer Sciences and Technology, Harbin Institute of Technology, Harbin, China \\ Email: " henggui.zhang@,Manchester.ac.uk
}

Received 22 October 2013; revised 25 November 2013; accepted 8 December 2013

Copyright (C) 2013 Ismail Adeniran et al. This is an open access article distributed under the Creative Commons Attribution License, which permits unrestricted use, distribution, and reproduction in any medium, provided the original work is properly cited.

\section{ABSTRACT}

Introduction: The 12-lead electrocardiogram (ECG) is the most widely-used tool for the detection and diagnosis of cardiac conditions including myocardial infarction and ischemia. It has therefore been a focus of cardiac modeling. However, the most contemporary in silico ECG investigations of the intact heart have assumed a static heart and ignored the mechanical contraction that is an essential component of cardiac function. The aim of this study was to utilize electromechanically coupled human ventricle models to explore the consequences of ventricular mechanical contraction on the ECG profiles. Methods and Results: Biophysically detailed human ventricular cell models incorporating contractile activity and a stretchactivated current $\left(I_{s a c}\right)$ were incorporated into a $3 D$ human ventricular model within a human torso, from which 12-lead ECGs were computed at a stimulation rate of $1 \mathrm{~Hz}$. Compared to the static model, ventricular contraction without $I_{\text {sac }}$ had little effect on the QRS complex, but shifted the T-wave peak leftwards and reduced its peak amplitude. With $I_{\text {sac }}$, ventricular mechanical contraction increased the QRS duration by $23 \%$ and QT interval by $5 \%$. Conclusion: Mechanical contraction of the heart has a significant effect on the morphology and characteristics of the ECG particularly on the T-wave. The alteration of the cell membrane kinetics by stretch via $I_{\text {sac }}$ further exacerbates these effects. Our simulation data suggest that mechanical contraction should be considered in the interpretation of ECGs in pathological conditions, especially those in which mechanical contraction of the heart is impaired.

Keywords: Ventricles; Mechanical Contraction;
Electrophysiology; Simulation; ECG

\section{INTRODUCTION}

The 12-lead electrocardiogram (ECG) is used to understand a person's cardiac electrical activity by measuring the electrical potential on the body surface in order to obtain diagnostic information on the status of the heart. Common ECG monitoring' uses include the detection of complex arrhythmias, shortened or prolonged QT intervals, ST-segment elevation and ischemia monitoring [1-3]. The 12-lead ECG system consists of six frontal plane leads (Lead I, Lead II, Lead III, aVR, aVL and aVF) and six chest leads $\left(\mathrm{V}_{1}-\mathrm{V}_{6}\right)$ [1-3]. Though being the most widely-used cardiac diagnostic tool, the ECG has some shortcomings, e.g., low sensitivity for detecting acute inferior myocardial infarction (its sensitivity is only approximately 60\%) [4]. Complex ECG patterns associated with left bundle branch block (LBBB), ventricular-paced rhythm (VPR) and left ventricular hypertrophy $(\mathrm{LVH})$ reduce the ability of the ECG to detect acute coronary ischemic change and acute myocardial infarction [5].

Biophysically detailed computer models of the heart that relate cardiac cellular mechanisms to a clinical measurement of ECG may establish a correlation atlas between ECG characteristics and various pathological conditions. This may be beneficial for mitigating the shortcomings of the use of clinical ECGs for diagnosing cardiac diseases. However, the majority of cardiac modelling studies have focused mainly on the electrical activity of the heart, with an assumption that the heart is stationary in the thorax [6-10]. This assumption ignores the fact that the heart is a mechanical pump, which undergoes rhythmic mechanical contractions in response to cardiac electrical excitation waves. The mechanical contraction alters the geometry of the heart as well as the cardiac 
electrical excitation via the mechanism of mechanoelectric feedback (MEF) [11-14].

It can be anticipated that the motion of the heart during the cardiac cycle alters the relative position of the ECG leads on the body surface to the electrical signal sources in the heart, as well as the anisotropic conductivity of the electrical propagation within the torso; all of which may have influences on the ECG, therefore, producing differences to the ECG characteristics is compared to a stationary heart, particularly during the T-wave when the heart is subjected to maximum systolic pressure $[2,15]$. In addition, in response to changes in volume load or contractile state (changing geometry), the heart regulates its electrical activity via MEF $[11,16,17]$, which activates stretch-activated channels (SACs) $[18,19]$ that regulate cardiac cell action potentials (APs), such as prolongation or shortening $[13,20,21]$ of AP duration (APD), changes of AP morphology and AP refractory properties (such as the diastolic depolarisation and premature excitation) [11,22-24]. However, it is incompletely understood how these changes of cardiac geometry and electrophysiology influence the body surface ECG. Therefore, the aim of this study was to investigate the consequences of ventricular wall motion on the 12-lead ECG in the absence and presence of a stretch-activated current $\left(I_{s a c}\right)$ during the cardiac cycle.

\section{MATERIAL AND METHODS}

\subsection{Single Cell Electromechanical Model}

For simulating electrophysiology (EP), we utilized the O'Hara-Rudy (ORd) human ventricular single cell model [25], which was developed from undiseased human ventricle data and recapitulates human ventricular cell electrical and membrane channel properties, as well as the transmural heterogeneity of ventricular action potential (AP) across the ventricular wall [25]. The ORd model also reproduces $\mathrm{Ca}^{2+}$ versus voltage-dependent inactivation of L-type $\mathrm{Ca}^{2+}$ current and $\mathrm{Ca}^{2+} /$ calmodulin-dependent protein kinase II (CaMK) modulated rate dependence of $\mathrm{Ca}^{2+}$ cycling [25]. For simulating cellular mechanical properties, we used the Rice et al. myofilament (MM) model [26]. This model was chosen as it is based on the cross-bridge cycling model of cardiac muscle contraction and is able to replicate a wide range of experimental data including steady-state force-sarcomere length (F-SL), force-calcium and sarcomere length-calcium relationships [26].

The intracellular calcium concentration $\left[\mathrm{Ca}^{2+}\right]_{i}$ from the EP model was used as the coupling link to the MM model. $\left[\mathrm{Ca}^{2+}\right]_{i}$ produced as dynamic output from the EP model during the time course of the AP served as input to the MM model from which the amount of $\mathrm{Ca}^{2+}$ bound to troponin was calculated. The formulation of the myoplasmic $\mathrm{Ca}^{2+}$ concentration in the EP model is:

$$
\begin{aligned}
\frac{\mathrm{d}\left[\mathrm{Ca}^{2+}\right]_{i}}{\mathrm{~d} t}= & \beta_{C a i} \cdot\left(-\left(I_{p C a}+I_{C a b}-2 \cdot I_{\text {NaCa,i }}\right) \cdot \frac{A_{c a p}}{2 \cdot F \cdot v_{\text {myo }}}\right. \\
& \left.-J_{\text {up }} \cdot \frac{v_{\text {nsr }}}{v_{\text {myo }}}+J_{\text {diff }, C a} \cdot \frac{v_{s s}}{v_{\text {myo }}}\right)
\end{aligned}
$$

where $\beta_{C a i}$ is the buffer factor for $\left[\mathrm{Ca}^{2+}\right], I_{p C a}$ is the sarcolemmal $\mathrm{Ca}^{2+}$ pump current, $I_{C a b}$ is the $\mathrm{Ca}^{2+}$ background current, $I_{N a C a, i}$ is the myoplasmic component of $\mathrm{Na}^{+} / \mathrm{Ca}^{2+}$ exchange current, $A_{\text {cap }}$ is capacitive area, $F$ is the Faraday constant, $v_{\text {myo }}$ is the volume of the myoplasmic compartment, $v_{n s}$ is the volume of the network sarcoplasmic reticulum compartment, $v_{s s}$ is the volume of the subspace compartment, $J_{u p}$ is the total $\mathrm{Ca}^{2+}$ uptake flux, via SERCA pump from myoplasm to the network sarcoplasmic reticulum and $J_{\text {diff,Ca }}$ is the flux of the diffusion of $\mathrm{Ca}^{2+}$ from the subspace to the myoplasm. $\beta_{\text {Cai }}$ is formulated as:

$$
\beta_{\text {Cai }}=\frac{1}{1+\frac{[\mathrm{CMDN}] \cdot K_{m, \mathrm{CMDN}}}{\left(K_{m, \mathrm{CMDN}}+\left[\mathrm{Ca}^{2+}\right]_{i}\right)^{2}}+\frac{[\mathrm{TRPN}] \cdot K_{m, \mathrm{TRPN}}}{\left(K_{m, \mathrm{TRPN}}+\left[\mathrm{Ca}^{2+}\right]_{i}\right)^{2}}}
$$

where [CMDN] and [TRPN] are the calmodulin and troponin $\mathrm{Ca}^{2+}$ buffers in the myoplasm respectively, and $K_{m \text {,CMDN }}$ and $K_{m \text {,TRPN }}$ are the half-saturation concentrations of calmodulin and troponin respectively.

In the original ORd model, Eq.2 considers $\mathrm{Ca}^{2+}$ binding to both calmodulin and troponin. However, as the MM model implements actual regulatory sites for the apparent $\mathrm{Ca}^{2+}$ binding to troponin, Eq.2 was modified to:

$$
\beta_{\mathrm{Cai}}=\frac{1}{1+\frac{[\mathrm{CMDN}] \cdot K_{m, \mathrm{CMDN}}}{\left(K_{m, \mathrm{CMDN}}+\left[\mathrm{Ca}^{2+}\right]_{i}\right)^{2}}}
$$

Now, the EP model only handles $\mathrm{Ca}^{2+}$ binding to calmodulin with the MM model handling $\mathrm{Ca}^{2+}$ binding to troponin. The flux of the binding of $\mathrm{Ca}^{2+}$ to troponin via the MM model was incorporated into the EP model via Eq.1 as follows:

$$
\begin{aligned}
\frac{\mathrm{d}\left[\mathrm{Ca}^{2+}\right]_{i}}{\mathrm{~d} t}= & \beta_{\text {Cai }} \cdot\left(-\left(I_{p C a}+I_{C a b}-2 \cdot I_{\text {NaCa,i }}\right) \cdot \frac{A_{\text {cap }}}{2 \cdot F \cdot v_{\text {myo }}}\right. \\
& \left.-J_{\text {up }} \cdot \frac{v_{\text {nsr }}}{v_{\text {myo }}}+J_{\text {diff }, \text { Ca }} \cdot \frac{v_{\text {ss }}}{v_{\text {myo }}}-\frac{J_{\text {Trop }}}{1000}\right)
\end{aligned}
$$

where $J_{\text {Trop }}$ is the flux of $\mathrm{Ca}^{2+}$ binding to troponin. The combination of all state variables from the EP model 
with the MM model and the substitution of Eq.3 and Eq.4 for Eqs.1 and 2 yielded a human ventricular myocyte electromechanical cell model.

\subsection{Stretch-Activated Current}

In accord with previous studies [19,27-31], we incorporated a stretch-activated current $\left(I_{\text {sac }}\right)$ into the electromechanics model using the following formulation:

$$
I_{\text {sac }}=G_{\text {sac }} \cdot P_{m} \cdot\left(V_{m}-E_{\text {sac }}\right)
$$

where $G_{s a c}$ and $E_{\text {sac }}$ are the maximum channel conductance and reversal potential of the SAC respectively. In the electromechanics model, $E_{s a c}$ was typically set to $-6.3 \mathrm{mV}$ and describes the experimentally observed depolarising effect of the channel $[32,33] . V_{m}$ is the membrane potential and $P_{m}$ is the channel's open probability modelled as:

$$
P_{m}=\frac{1}{1+\mathrm{e}^{-\left(\frac{\varepsilon-\varepsilon_{1 / 2}}{k_{e}}\right)}}
$$

where $\varepsilon$ and $\varepsilon_{1 / 2}$ are the strain (with an explicit dependence on the sarcomere length) and half-activation strain respectively, $k_{e}=0.02[19,29,34]$ is the activation slope.

The SAC is assumed to be permeable to $\mathrm{Na}^{+}, \mathrm{K}^{+}$and $\mathrm{Ca}^{2+}[19,30,35]$ in the ratio $1: 1: 1$ with $I_{\text {sac }}$ therefore defined as:

$$
I_{s a c}=I_{s a c, N a}+I_{s a c, K}+I_{s a c, C a}
$$

where $I_{s a c, N a}, I_{s a c, K}$ and $I_{s a c, C a}$ are the contributions of $\mathrm{Na}^{+}$, $\mathrm{K}^{+}$and $\mathrm{Ca}^{2+}$ to $I_{\text {sac }}$.

\subsection{Tissue Mechanics Model}

We modelled cardiac tissue mechanics within the theoretical framework of nonlinear elasticity $[36,37]$ as an inhomogeneous, anisotropic, nearly incompressible nonlinear material similar to previous studies [27,38-42]. We used a two-field variational principle with the deformation $\boldsymbol{u}$ and the hydrostatic pressure $\boldsymbol{p}$ as the two fields $[37,43,44] . \boldsymbol{p}$ is utilised as the Lagrange multiplier to enforce the near incompressibility constraint. Thus, the total potential energy functional $\Pi$ for the mechanics problem is formulated as:

$$
\Pi(u, p)=\Pi_{i n t}(u, p)+\Pi_{\text {ext }}(u)
$$

where $\Pi_{\text {int }}(u, p)$ is the internal potential energy or total strain energy of the body and $\Pi_{\text {ext }}(u)$ is the external potential energy or potential energy of the external loading of the body. As in previous studies [38,41,42,45], in the absence of body forces, and assuming that the body is always in instantaneous equilibrium and no inertia effects, the coordinates of the deformed body satisfies the steady-state equilibrium equation with near incompressibility enforced.
According to standard variational principles, equilibrium is derived by searching for critical points of (Eq.8) in suitable admissible displacement and pressure spaces $\hat{U}$ and $\hat{P}$. The corresponding Euler-Lagrange equations resulting from (Eq.8) lead to solving the problem [44,46-49]:

$$
\begin{aligned}
& \text { Find }(u, p) \text { in } \hat{U} \times \hat{P} \quad \text { such that: } \\
& \int_{\Omega} \frac{\partial \hat{W}}{\mathrm{~d} F}(x, I d+\nabla u): \nabla v \mathrm{~d} x \\
& -\int_{\Omega} p \frac{\partial \mathrm{det}}{\mathrm{d} F}(I d+\nabla u): \nabla v \mathrm{~d} x=\int_{\Omega} g \cdot v \mathrm{~d} s \quad \forall v, u \in \hat{U} \\
& \quad \int_{\Omega} q[\operatorname{det}(I d+\nabla u)-1] \mathrm{d} x=0 \quad \forall q, p \in \hat{P}
\end{aligned}
$$

where $\hat{U}$ and $\hat{P}$ are the admissible variation spaces for the displacements and the pressures, respectively. $F=I d+\nabla u$ is the deformation gradient, $v$ is a test function and $\hat{W}$ is the material stored energy function and corresponds to the density of elastic energy locally stored in the body during the deformation.

With the axes of the geometry aligned to the underlying tissue microstructure [50,51], the second PiolaKirchhoff stress tensor $S$, obtained from the directional derivative of (Eq.8) in the direction of an arbitrary virtual displacement and which relates a stress to a strain measure [37,43] and a manipulation of Eq.9 is defined as:

$$
S=\frac{1}{2}\left(\frac{\partial W}{\partial E_{M N}}+\frac{\partial W}{\partial E_{N M}}\right)-p C_{M N}^{-1}+S_{\text {Active Tension }}
$$

where $W$ is a strain energy function that defines the constitutive behaviour of the material, $E$ is the Green-Lagrange strain tensor that quantifies the length changes in a material fibre and angles between fibre pairs in a deformed solid, $C$ is the Right-Cauchy green strain tensor, $p$ is a Lagrange multiplier (referred to as the hydrostatic pressure in the literature) used to enforce incompressibility of the cardiac tissue, $S_{\text {Active Tension }}$ is a stress tensor incorporating active tension from the electromechanics cell model and enables the reproduction of the three physiological movements of the ventricular wall: longitudinal shortening, wall thickening and rotational twisting [5258].

For the strain energy function $W$, we used the Guccione constitutive law [59] given by:

$$
W=C_{1} \mathrm{e}^{Q}
$$

where

$$
\begin{aligned}
Q= & C_{2} E_{11}^{2}+C_{3}\left(E_{22}^{2}+E_{33}^{2}+2 E_{23}^{2}\right) \\
& +2 C_{4}\left(E_{12} E_{21}+E_{13} E_{31}\right)
\end{aligned}
$$

Following previous work [27,60], $C_{1}=0.831 \mathrm{kPa}$, 
$C_{2}=14.31, C_{3}=4.49, C_{4}=10 . E_{i j}$ are the components of the Green-Lagrange strain tensor.

\subsection{Tissue Electrophysiology Model}

The monodomain representation [61-63] of cardiac tissue was used for the electrophysiology model with a modification (the incorporation of the Right Cauchy Green deformation tensor $\boldsymbol{C}$ ), which allows the monodomain equation to take into account the effect of the deforming tissue, similar to previous studies $[38,42,64]$ :

$$
C_{m} \frac{\mathrm{d} V}{\mathrm{~d} t}=-\left(I_{\text {ion }}+I_{\text {stim }}\right)+\nabla \cdot\left(D C^{-1} \nabla V\right)
$$

where $C_{m}$ is the cell capacitance per unit surface area, $V$ is the membrane potential, $I_{i o n}$ is the sum of all transmembrane ionic currents from the electromechanics single cell model, $I_{\text {stim }}$ is an externally applied stimulus and $D$ is the diffusion tensor. In simulations, intracellular conductivities in the fibre, cross-fibre and sheet directions were set to $3.0,0.1$ and $0.31525 \mathrm{~ms} \cdot \mathrm{mm}^{-1}$ respectively. These gave a conduction velocity of $65 \mathrm{~cm} \cdot \mathrm{s}^{-1}$ in the fibre direction along multiple cells, which is close to the value $70 \mathrm{~cm} \cdot \mathrm{s}^{-1}$ observed in the fibre direction in human myocardium [65].

\subsection{Torso Model}

The electrical potential in the torso (Figure 1(B)) is obtained via the Poisson equation:

$$
\nabla \cdot\left(D_{T} \nabla V_{T}\right)=0
$$

where $D_{T}$ is the torso conductivity and $V_{T}$ is the electrical potential in the torso. The torso is modelled as a passive conductor surrounded by air. Consequently, the normal component of its outer surface is zero leading to the first boundary condition:

$$
\begin{aligned}
& n \cdot\left(D_{T} \nabla V_{T}\right)=0 \\
& x \in \partial T
\end{aligned}
$$

where $n$ is the outward unit normal on the torso surface, $\partial T$ is the outer surface of the torso. The torso is a conductor surrounding the ventricles. Therefore, from the conservation of charge and current, on the boundary between the ventricles and the torso, the normal component of the current in the ventricles must equal the normal component of the current in the surrounding torso. Since there cannot be a discontinuity in the potentials on the boundary of two directly connected volume conductors, i.e., the ventricles and the torso, this condition implies the following boundary condition:

$$
\begin{aligned}
& V_{T}=V_{\text {DVENTRICLES }} \\
& x \in \text { OVENTRICLES }
\end{aligned}
$$

where $V_{\partial V E N T R I C L E S}$ is the electrical potential on the sur- face between the ventricles and the torso. The torso conductivity was set to $0.3 \mathrm{~ms} \cdot \mathrm{mm}^{-1}$.

\subsection{Computing the 12-Lead ECGs}

We computed the ECGs according to the standard definitions $[3,66]$ (Figure 1(B)). The limb leads were calculated as follows:

$$
\begin{aligned}
& \text { Lead } I=\phi_{L A}-\phi_{R A} \\
& \text { Lead } I I=\phi_{L L}-\phi_{R A} \\
& \text { Lead } I I I=\phi_{L L}-\phi_{L A}
\end{aligned}
$$

where $L A, L L$ and $R A$ refer to the left arm, left leg and right arm respectively and $\phi_{X}$ is the potential of the appropriate lead. The augmented limb leads were calculated as:

$$
\begin{aligned}
& a V F=\operatorname{Lead} I I-\frac{1}{2}(\operatorname{Lead} I) \\
& a V L=\operatorname{Lead} I-\frac{1}{2}(\operatorname{Lead} I I) \\
& a V R=-\frac{1}{2}(\operatorname{Lead} I+\text { Lead } I I)
\end{aligned}
$$

The precordial leads, $\mathrm{V}_{1}-\mathrm{V}_{6}$ are located over the left chest as shown in Figure 1(B). Their potentials are measured directly from their locations.

\subsection{Computational Methods}

\subsubsection{Geometry and Meshes}

The 3D simulations were carried out on a DT-MRI reconstructed anatomical human ventricle geometry (Figure 1(A)), incorporating anisotropic fibre orientation (Figure 1(A)), from a healthy 34-year old male. This had a spatial resolution of $0.2 \mathrm{~mm}$ and approximately 24.2 million nodes in total and was segmented into distinct ENDO (60\%), MCELL (30\%) and EPI (10\%) regions (Figure 1(A)). The chosen cell proportion in each region reflects experimental data for cells spanning the left ventricular wall of the human heart [67]. The conditional activation sites were determined empirically across the ventricle wall and were validated by reproducing the activation sequence and QRS complex in the measured 64-channel ECG [68] of that person (Figure 1(A)).

\subsubsection{Solving the Electromechanics Problem}

The electromechanics problem consists of two subproblems: the electrophysiology problem and the mechanics problem. The electrophysiology problem Eq.10 was solved with a Strang splitting method [69] ensuring that the solution is second-order accurate. It was discretised in time using the Crank-Nicholson method [70], which is also second-order accurate and discretised in space with Finite Elements [48,49,70,71]. $I_{\text {ion }}$ in Eq.10 represents the single cell electromechanics model from 

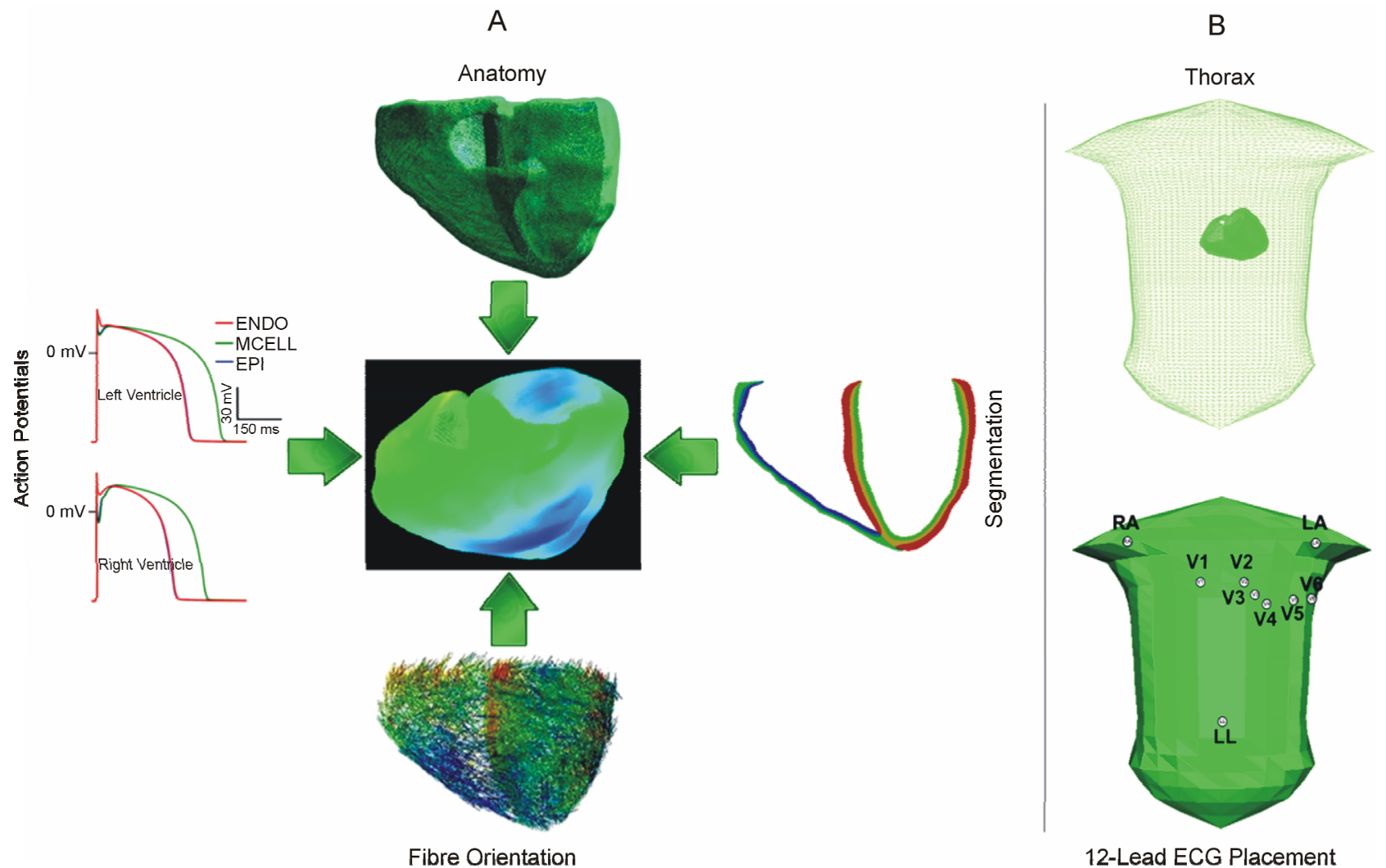

Figure 1. Schematic diagram of the 3D electromechanical ventricular system. (A) Left and right ventricular single cell electromechanical models incorporated into a 3D human ventricular geometry with fibre orientations and segmented into distinct right and left ventricular endocardial, mid-myocardial and epicardial regions resulting in the electrical activation sequence of mechanically contracting 3D human ventricles. (B) Thorax model constructed from CT images with embedded ventricles (top) and electrode placements for 12-lead ECG computation (bottom).

which the active tension input to the tissue mechanics model for contraction is obtained. The system of ordinary differential equations (ODE) composing $I_{\text {ion }}$ was solved with a combination of the Rush-Larsen scheme [72] and the CVODE solver [73,74].

The mechanics problem Eq.8 was also solved using the Finite Element Method using the automated scientific computing library, FEniCS [75]. The resulting nonlinear system of equations was solved iteratively using the Newton method to determine the equilibrium configuration of the system. The value of the Right Cauchy Green Tensor $C$ was then used to update the diffusion coefficient tensor in (Eq.14). Over a typical finite element domain, $P_{2}$ elements $[48,49,71]$ were used to discretize the displacement variable $\boldsymbol{u}$, while the pressure variable $\boldsymbol{p}$ was discretised with $P_{1}$ elements [48,49,71]. This $\mathrm{P}_{2}-\mathrm{P}_{1}$ mixed finite element has been proven to ensure stability [75-77] and an optimal convergence rate $[71,76,78]$.

The algorithm for solving the full electromechanics problem is as follows:

1) Determine the initial deformation and obtain the value of the Right Cauchy Green Tensor $C$.

2) While time $<t_{\text {end }}$ : a) Solve the electrophysiology problem for $\Delta \mathrm{t}_{\text {mechanics }}=$ 1 ms with $C$ as input and active tension $T_{a}$ as output $\left(\Delta \mathrm{t}_{\text {electrophysiology }}=0.01 \mathrm{~ms}\right)$.

b) Project $T_{a}$ from the electrophysiology mesh onto the mechanics mesh.

c) Solve the mechanics problem with $T_{a}$ as input and $C$ as output.

\section{RESULTS}

\subsection{Single Cell Electromechanical Simulations}

\subsubsection{Simulations without Incorporation of $\boldsymbol{I}_{\mathrm{sac}}$}

We first investigated at the cellular level, how mechanical contraction (via the MEF mechanism) affected cardiac electrical activity. Without consideration of $I_{\text {sac }}$, the simulated electrical and mechanical behaviors at a stimulation frequency of $1 \mathrm{~Hz}$ are shown in Figure 2 for the ENDO, MCELL and EPI cell types (Figure 2). Figure 2(A) shows the simulated action potentials (APs) for the three cell types. The computed action potential duration at $90 \%$ repolarization $\left(\mathrm{APD}_{90}\right)$ was $228 \mathrm{~ms}$ for the EPI cell, $339 \mathrm{~ms}$ for the MCELL and $269 \mathrm{~ms}$ for the ENDO cell. Figure 2 also shows the corresponding 

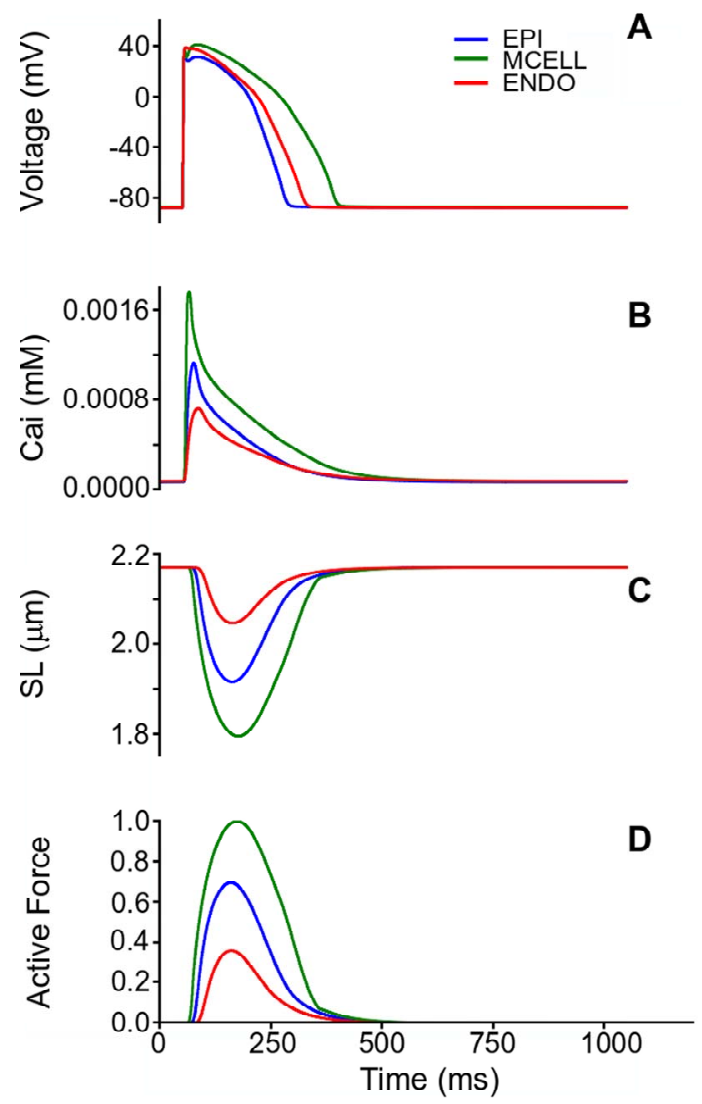

Figure 2. Simulation of ventricular electromechanical characteristics (without $I_{\text {sac }}$ ). (A) Action potentials in the EPI (blue), MCELL (green) and ENDO (red) cell models. (B) $\mathrm{Ca}^{2+}$ transients in the EPI (blue), MCELL (green) and ENDO (red) cell models. (C) Sarcomere length in the EPI (blue), MCELL (green) and ENDO (red) cell models. (D) Active force in the EPI (blue), MCELL (green) and ENDO (red) cell models. Values are normalised to MCELL maximum active force for each cell type.

$\left[\mathrm{Ca}^{2+}\right]$. (Figure 2(B)), the sarcomere length (SL) shortening (Figure 2(C)) and the active force (Figure 2(D)). The correlation between the action potential and the $\left[\mathrm{Ca}^{2+}\right]$ agrees with experimental data $[15,19,20$, $22,23,25,26,79]$. Of note is the fact that the $\left[\mathrm{Ca}^{2+}\right]$. amplitude is smallest for the ENDO cell (Figure 2(B)) despite it having a greater $\mathrm{APD}_{90}$ than the EPI cell (Figure 2(A)). This was because the model considered a greater amount of $\left[\mathrm{Ca}^{2+}\right]$, buffered by $\mathrm{Ca}^{2+} /$ calmodulin-dependent kinase II (CaMK) in the ENDO cell type as compared to the EPI cell type [25] as observed in undiseased non-failing human ventricles. This observation was also consistent with the observation from the ORd electrophysiology model [25]. Consequently, the amplitudes of the SL shortening (Figure 2(C)) and active force (Figure 2(D)) in the ENDO cell type are the smallest among the three cell types. The simulated larger $\left[\mathrm{Ca}^{2+}\right]_{i}$ (and hence greater contractility) in the MCELL compared to the EPI and ENDO cells was also consistent with experimental data [79].

We further investigated the force-frequency relationship (FFR) of the electromechanics model. The FFR was obtained by stimulating the single cell at different frequencies for 1000 beats until steady state was reached. The maximum force developed at each stimulation frequency was recorded and plotted against the stimulation frequency. Results from the EPI cell model are shown in Figure 3 (results from the other two cell types were similar). In the considered frequency range, $0.5-3 \mathrm{~Hz}$, the simulated FFR showed the Bowditch staircase or Treppe effect [80-82], which matched experimental data [81].

As the normal heart rate is near $1 \mathrm{~Hz}$, all subsequent simulations in this study were carried out at $1 \mathrm{~Hz}$ (Figure 3; dashed vertical blue line).

\subsubsection{Simulations with Incorporation of $\boldsymbol{I}_{\text {sac }}$}

We then investigated how $I_{s a c}$ affected the cardiac electrical and mechanical activity at the single cell level. Figure 4 shows the results from the three cell models, with consideration of $I_{\text {sac }}$ that are permeable to $\mathrm{Na}^{+}, \mathrm{K}^{+}$ and $\mathrm{Ca}^{2+}$ with a permeability ratio $\mathrm{Na}^{+}: \mathrm{K}^{+}: \mathrm{Ca}^{2+}=1: 1: 1$. Compared to the case in which $I_{s a c}$ was absent, $I_{\text {sac }}$ produced an elevation in the resting potential for the EPI,

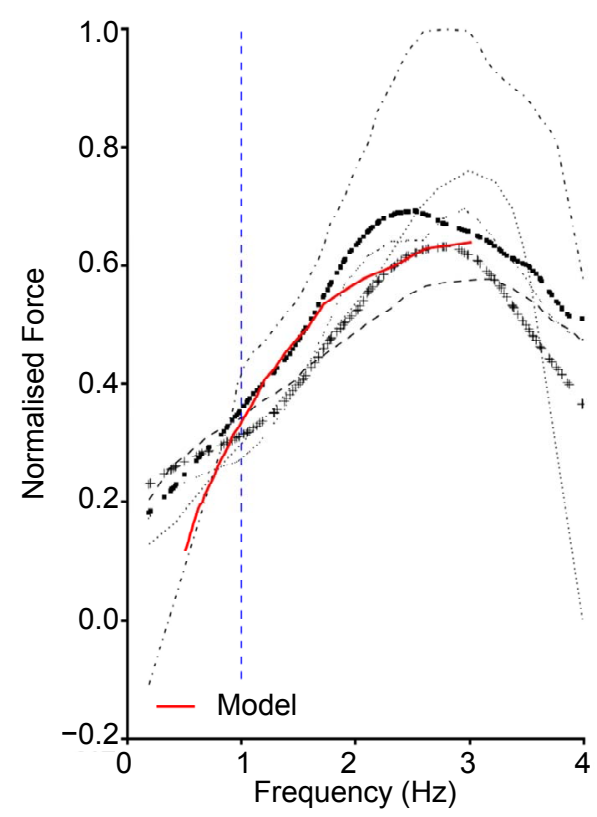

Figure 3. Plot of steady state normalised active force vs. heart rate using the EPI cell model. Red continuous line represents the WT electromechanics model while symbols represent experimental data from non-failing control preparations of human myocardium. Experimental data from Mulieri et al. [81]. The blue, vertical dashed line indicates the FFR at $1 \mathrm{~Hz}$. 

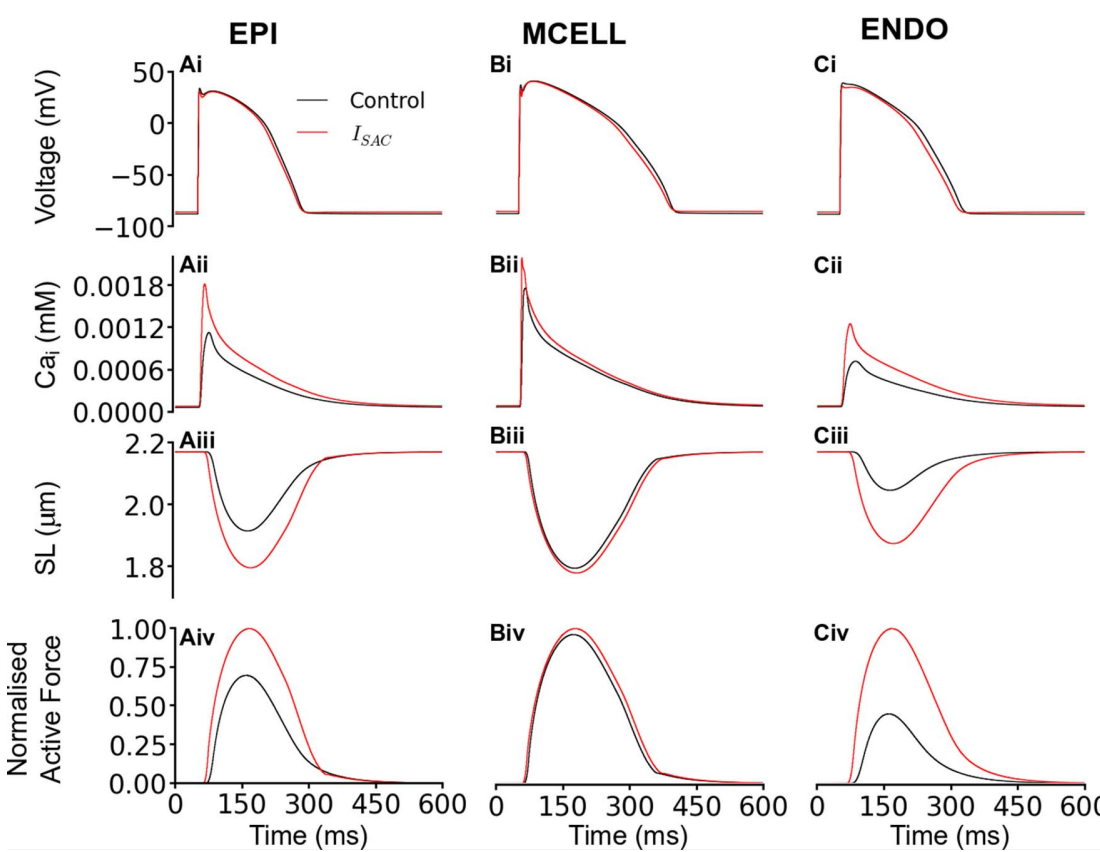

$\mathrm{Cii}$
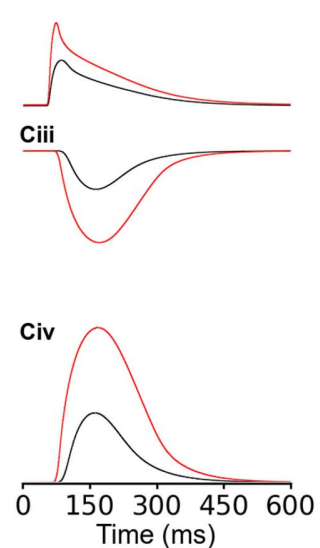

Figure 4. Single cell effects of $I_{s a c}$ on the electromechanics model. (Ai-Ci) Action potentials without stretch (black) and with stretch (red) in the EPI, MCELL and ENDO cell models. (Aii-Cii) $\mathrm{Ca}^{2+}$ transients without stretch (black) and with stretch (red) in the EPI, MCELL and ENDO cell models. (Aiii-Ciii) Sarcomere length without stretch (black) and with stretch (red) in the EPI, MCELL and ENDO cell models. (Aiv-Civ) Active force without stretch (black) and with stretch (red) in the EPI, MCELL and ENDO cell models. Values are normalised to maximum active force for each cell type with stretch.

MCELL and ENDO cells (the resting potential changed from $-87.5 \mathrm{mV}$ to $-85.9 \mathrm{mV}$ ) (Figures 4(Ai)-(Ci)). This is consistent with experimental observations $[13,35,83$, 84]. $I_{\text {sac }}$ also shortened the AP duration (EPI APD changed from $228 \mathrm{~ms}$ to $223 \mathrm{~ms}$ (Figure 4(Ai)), MCELL $\mathrm{APD}_{90}$ from $339 \mathrm{~ms}$ to $333 \mathrm{~ms}$ (Figure 4(Bi)) and ENDO $\mathrm{APD}_{90}$ from $269 \mathrm{~ms}$ to $257 \mathrm{~ms}$ ) (Figure 4(Ci)). This is also consistent with previous experimental studies which showed a stretch-related APD shortening [12,13,21,22,84] and control data from a previous modelling study from our laboratories on electromechanical consequences of the Short QT Syndrome [27]. In the model, the most significant consequences of inclusion of $I_{s a c}$ were upon $\left[\mathrm{Ca}^{2+}\right]_{i}$ and the contractile activity. $I_{s a c}$ increased the $\left[\mathrm{Ca}^{2+}\right]$ amplitude by $60 \%$ in the EPI; $23 \%$ in the MCELL and $72 \%$ in the ENDO cell model (Figures 4(Aii)-(Cii)), which consequently led to greater SL shortening (Figures 4(Aiii)-(Ciii)) and greater contractile force by $42 \%$ in the EPI, $3.5 \%$ in the MCELL and $119 \%$ in the ENDO cells (Figures 4(Aiv)-(Civ)). The increase of the $\left[\mathrm{Ca}^{2+}\right]_{i}$ amplitude can be attributed to the permeability of the SACs to $\mathrm{Na}^{+}, \mathrm{K}^{+}$and $\mathrm{Ca}^{2+}$, the activation of which brought more $\mathrm{Na}^{+}$and $\mathrm{Ca}^{2+}$ into the cell that increased $\left[\mathrm{Na}^{+}\right]_{i}$ and $\left[\mathrm{Ca}^{2+}\right]_{i}$. These results are similar to those observed previously with a different human ventricular cell model [27]. During stretch, the increase in $\left[\mathrm{Ca}^{2+}\right]_{i}$ would then increase $\left[\mathrm{Ca}^{2+}\right]_{i}$ via the activation of the reverse-mode of the $\mathrm{Na}^{+}-\mathrm{Ca}^{2+}$ exchanger leading to greater contractility as has been demonstrated in several studies [19,27,86-90]. For extensive coverage of further SAC and mechano-electric feedback mechanisms, see the study by Youm et al. [19].

\subsection{2-Lead ECG}

At the intact tissue level, we used the 3D heart-torso model to investigate the functional impact of the mechanical contraction of the heart on the body surface potential, and therefore upon the characteristics of the 12-lead ECG. In simulations, the 12-lead ECG was obtained by incorporating the single cell electromechanics model into 3D anatomical ventricular geometry within the torso (see Figure 1). Three settings were considered: 1) static ventricles, 2) contracting ventricles with no $I_{s a c}$ and 3) contracting ventricles with $I_{s a c}$. The results obtained from settings 2 and 3 were compared with those from setting 1 .

Figure 5 shows the time course of simulated 12-lead ECGs. Compared to the static heart, contraction without $I_{\text {sac }}$ had minimal effect on the QRS complex in all the leads - its duration was decreased by $1.95 \%$; and the S-wave component was elevated by $1.86 \%$ (Figure 5). 


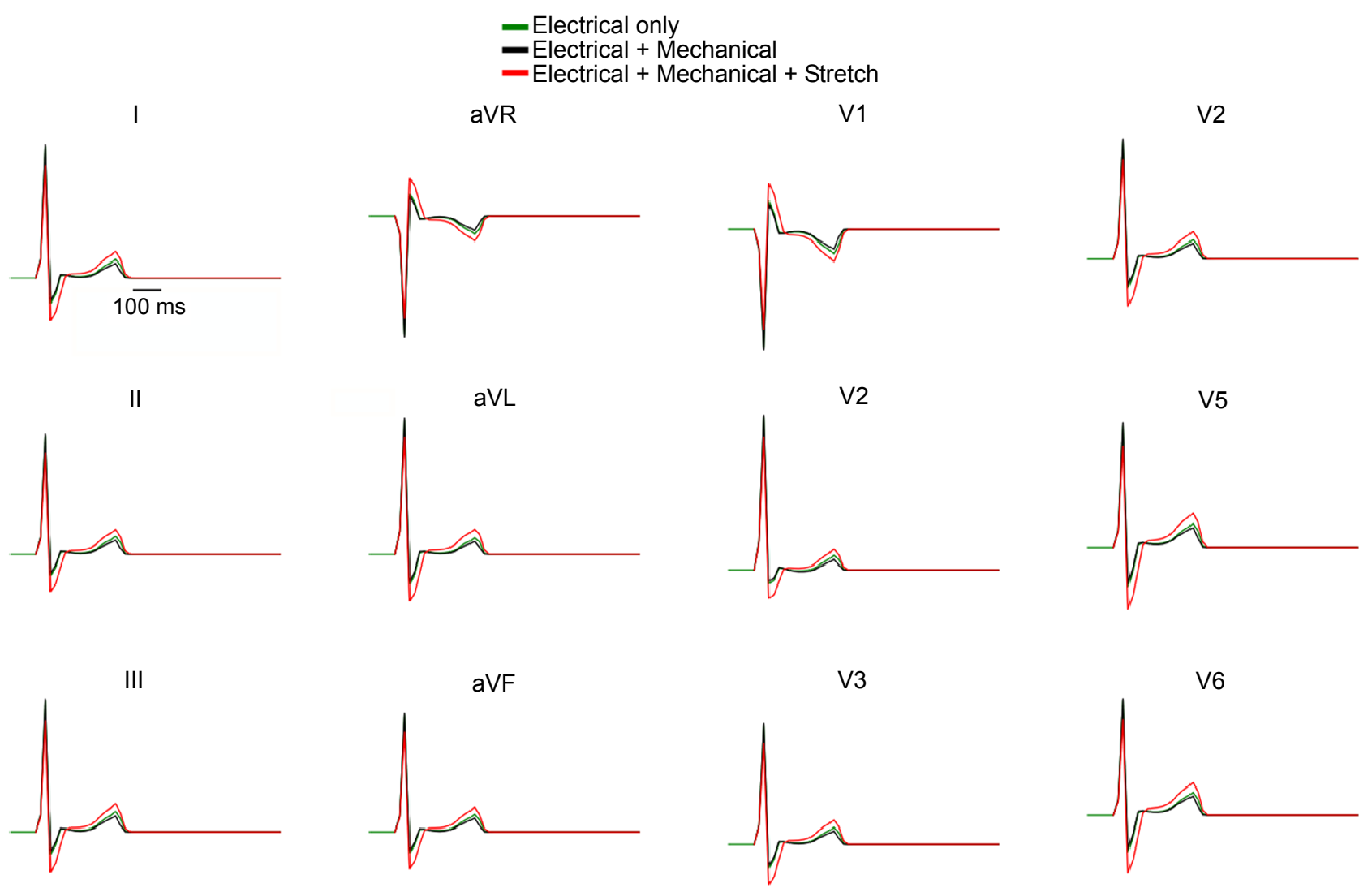

Figure 5. 12-lead ECG recordings from static ventricles without stretch (green), contracting ventricles without stretch (black) and from contracting ventricles with stretch (red).

Detailed analysis of the active force generated by a left ventricular (LV) cell during contraction showed nonnotable developed active force during the QRS complex as indicated by the dashed line in Figure 6. This is in agreement with clinical observations as during the QRS complex period of the cardiac cycle, the heart is undergoing isovolumic contraction $[2,91,92]$ with little active force developed particularly during the QR component. There was a leftward shift in the peak of the T-wave and a reduction in its peak amplitude $\left(\mathrm{T}_{\text {peak }}\right)$ by $18 \%$ (Figure 5); but the QT interval was unchanged. Clinically, the T-wave is the period of ventricular repolarisation, during which maximum systolic pressure occurs in a single cardiac cycle $[2,93,94]$.

Inclusion of $I_{\text {sac }}$ had more marked effects on the characteristics of the ECGs, such as the width and amplitude of the QRS and the QT interval. In simulations, inclusion of $I_{s a c}$ in the contraction heart model reduced the amplitude of the R-wave by $17 \%$ as compared to the static heart model. It also produced a more negative S-wave (by 59\%), a wider QRS duration (by $18 \%$ ), an elevated ST segment, a prolonged QT interval (by 5\%) and an increased $\mathrm{T}_{\text {peak }}$ (by 45\%). Table 1 summarizes the ECG properties for all three scenarios investigated.
Table 1. Effects of contraction with and without $I_{s a c}$ on the ECG.

\begin{tabular}{cccc}
\hline & $\begin{array}{c}\text { Electrical } \\
\text { only }\end{array}$ & $\begin{array}{c}\text { Electrical + } \\
\text { Contraction }\end{array}$ & $\begin{array}{c}\text { Electrical + } \\
\text { Contraction + Stretch }\end{array}$ \\
\hline QRS (ms) & 97.4 & 95.5 & 119.4 \\
QT (ms) & 361.1 & 361.1 & 380.6 \\
$\mathbf{T}_{\text {peak }}-\mathbf{T}_{\text {end }}(\mathbf{m s )}$ & 41.1 & 41.1 & 60.6 \\
$\begin{array}{c}\mathbf{T}_{\text {peak }} \text { amplitude } \\
(\%)\end{array}$ & $100 \%$ & $82.4 \%$ & $144.5 \%$ \\
\hline
\end{tabular}

\section{DISCUSSION}

\subsection{Summary of Major Findings}

At present, the 12-lead ECG is an invaluable and the most widely used tool for the detection and diagnosis of a broad range of cardiac conditions including myocardial infarction, ischemia, conduction and bundle branch blocks $[2,92]$. The widespread use of ECGs is based on comprehensive understanding of the correlation between cardiac electrophysiology and characteristics of ECGs. Changes in cardiac electrophysiology (e.g. changes in cellular membrane ion channel properties and/or intercellular electrical coupling) due to various cardiac diseases alter cardiac excitation wave propagation, leading 


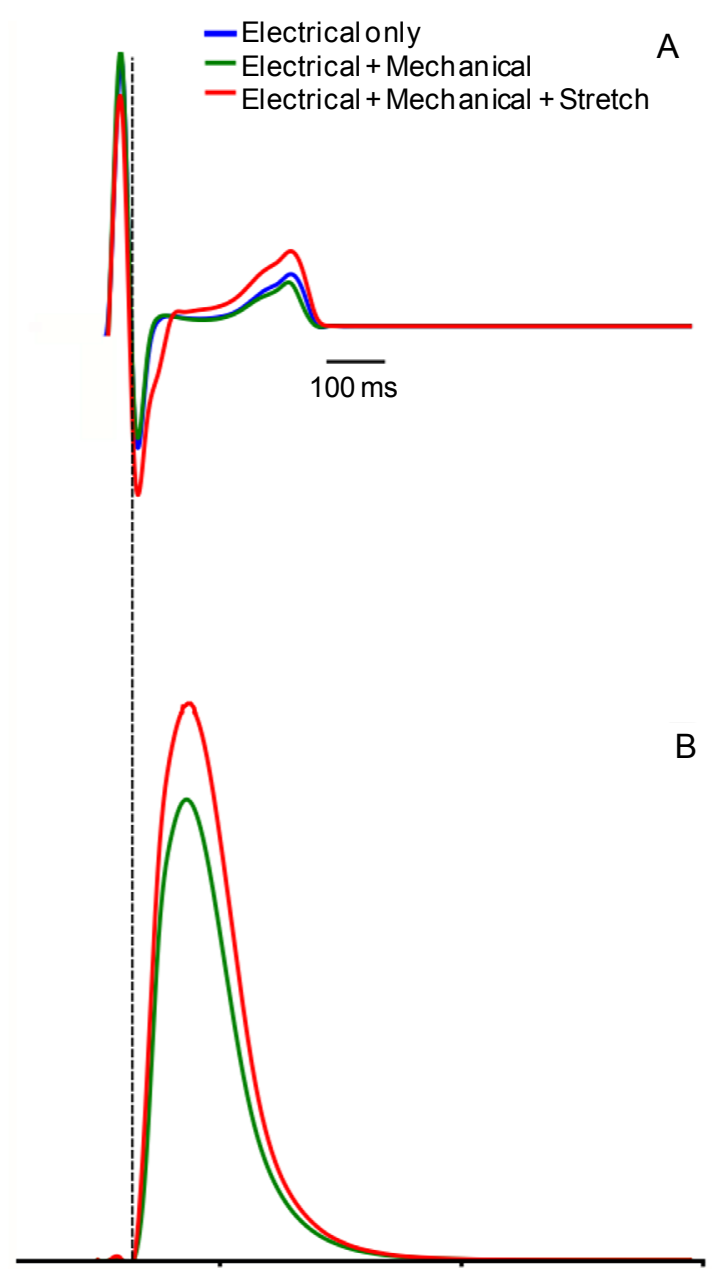

Figure 6. ECG and active force recordings from a left ventricular cell in static ventricles without stretch (green), contracting ventricles without stretch (black) and from contracting ventricles with stretch (red).

to an altered electrical field in and around the heart that varies with time during the cardiac cycle $[2,15,92]$. Such a changed electrical field surrounding the heart is reflected by changes in the ECG characteristics. Another important characteristic of the heart is the muscle contraction and relaxation, which also varies with time during the cardiac cycle $[2,15,92]$. In addition, in response to mechanical events such as stretch and volume load, the heart regulates its own electrical activity via MEF $[2,18,19]$; which includes the activation of SACs $[18,19$, 95]. So far, how cardiac mechanical contraction influences ECG characteristics is less well-understood. In the present study, we have incorporated biophysically detailed coupled electromechanical ventricular cell models into a 3D-anatomical human ventricle situated within a human thorax to investigate the effects of mechanical contraction with and without $I_{s a c}$ on the 12-lead ECG. Our simulations suggest that: 1) contraction without consideration of $I_{s a c}$ has no significant effect on the QRS complex, no effect on the QT interval, but shifts the $\mathrm{T}$-wave leftwards and reduces $\mathrm{T}_{\text {peak }}$ (Figure 5); 2) contraction with consideration of $I_{s a c}$ reduces the R-wave amplitude, widens the QRS complex duration, increases $\mathrm{T}_{\text {peak }}$ significantly, shifts the T-wave rightwards and increases the QT interval (Figure 5). These findings are dependent on the degree of stretch and are influenced by the magnitude of $I_{s a c}$. Several aspects of our findings merit more detailed discussion.

\subsection{Mechanistic Insights}

With mechanically contracting ventricles without consideration of $I_{\text {sac }}$, the QRS complex was not affected significantly, either in duration $(1.95 \%$ decrease $)$ or morphology (Figure 5). Contraction during the QRS complex is isovolumic [2,91,92], thus explaining the insignificant effect of contraction on the ECG during this period. Contraction of each myocyte in the intact tissue is not necessarily isometric, however, as each undergoes different length changes with time. Some myocytes contract isotonically, some isometrically whilst others contract eccentrically $[2,91,92,94]$. Therefore, even though the ventricular volume does not change substantially, the ventricle chamber geometry changes considerably [2,94, 96-98]. Consequently, compared to a static heart, the position of the cardiac electrical sources, the distance of the ventricles from the body surface and the varying anisotropic conductivity due to MEF are altered in a mechanically contracting heart; hence, there was a $1.95 \%$ decrease in QRS duration without $I_{\text {sac }}$. With consideration of $I_{s a c}$, these differential changes in myocyte lengths and hence ventricular geometry are exacerbated; hence, there was a greater and more significant effect of contraction with $I_{s a c}$ on the QRS complex (Figure 5). By the Frank-Starling law, with the increased stretch of the myocardial fibers during diastole by $I_{s a c}$, contractility would increase [2,94,99].

During the T-wave, ventricular contraction attains a maximum, after which ventricular pressure declines with ventricular repolarisation causing a decline in the active force of the myocytes [2,94,96-98]. The ventricular pressure during this period is $\sim 30 \%$ greater than during the QRS complex [2,94,96-98]. Therefore, during contraction, the aforementioned changes in ventricular geometry, the distance of the ventricles from the body surface and the varying anisotropic conductivity due to MEF are altered markedly compared to a static heart. This results in a marked effect on the T-wave; without $I_{\text {sac }}$, it is shifted leftwards and the $\mathrm{T}_{\text {peak }}$ is reduced in amplitude by $18 \%$. With $I_{\text {sac }}$, the myocardial fibers are stretched during diastole leading to increased contractility, which in turn increases systolic pressure [2,94,99] leading to a greater effect on the T-wave (Figure 5); $\mathrm{T}_{\text {peak }}$ is increased in amplitude significantly by $\sim 45 \%$ and QT 
interval is increased by $\sim 5 \%$.

\subsection{Relevance to Previous Studies}

Our simulations suggest that ventricular contraction alters 12-lead ECG morphology. This is consistent with previous studies [100-103]. In their study, Wei et al. [100] used MRI time sequences of the motion of a human ventricular geometry to compute 12-lead ECGs by mounting the geometry in a model of the human body. They found that ventricular motion reduced $T_{\text {peak }}$ with minimal change to the QRS complex. However, they did not consider the incorporation of $I_{\text {sac. }}$. Xia et al. [101] also obtained similar results with a human whole heart geometry mounted in a human torso but their simulations lacked the use of biophysically detailed electromechanical single cell models and the incorporation of $I_{s a c}$. Therefore, the present work is the first study to investigate the effects of $I_{\text {sac }}$ on the characteristics of simulated body surface 12-lead ECGs using anatomically detailed and mechanically contracting ventricles. The findings from the present study improve our understanding of the effects of electrical-mechanical coupling on the characteristics of ECG. This was achieved by 1) using biophysically detailed human ventricular myocyte models [25] coupled with the Rice et al. myofilament model [26]; employed with and without $I_{s a c}$ and 2) by demonstrating the importance of ventricular motion on the morphology, properties and subsequently interpretation of the 12 lead ECG.

\subsection{Limitations}

In addition to acknowledged limitations of both the ORd electrophysiology model [25] and the Rice et al. [26] myofilament model, $I_{s a c}$ density was based on prior studies [19,28-31], due to lack of experimental data on the $I_{s a c}$ from human ventricular myocytes. Additionally, the simulations here were performed at a single, physiologically relevant frequency $(1 \mathrm{~Hz})$, but rate-dependent differences in MEF have not been pursued in this initial study Experimentally observed effects of cycle length (restitution curve) [104] have also not been studied. These rate-dependent phenomena would constitute a valuable future line of investigation. It should also be acknowledged that $I_{s a c}$. may not be the only mechanism responsible for MEF (e.g. [105]) and that due to an absence of functional data in human myocytes, the electromechanical model lacks stretch sensitive $\mathrm{K}^{+}$channels (e.g. TREK). The model also lacks interactions between myocytes and fibroblasts, which have been proposed to contribute to ventricular MEF [106,107]. Whilst it would be useful for such components to be incorporated into future models, the advantage of the approach adopted here is that it has been possible to isolate and attribute with confidence electrical changes to the incorporation of
$I_{\text {sac }}$. Finally, the use of a ventricular computational fluid dynamics model to determine pressure boundary conditions would allow a more realistic pressure profile. Although it is important that these potential limitations are stated, they do not fundamentally influence the principal conclusions of this study.

\section{CONCLUSION}

With the use of a biophysically detailed electromechanical human ventricular single cell model incorporated into a thorax-mounted human ventricular geometry, we have shown that the morphology and properties of the ECG are dependent on ventricular contraction. We have also shown that cellular stretch incorporated at the single cell level as an SAC has a significant influence on the ECG in a mechanically contracting ventricle.

\section{ACKNOWLEDGEMENTS}

This work was supported by project grants from Engineering and Physical Science Research Council UK (EP/J00958X/1; EP/I029826/1), the British Heart Foundation (FS/08/021), the Natural Science Foundation of China (61179009) and the University of Manchester.

\section{REFERENCES}

[1] Drew, B.J., Califf, R.M., Funk, M., Kaufman, E.S., Krucoff, M.W., Laks, M.M., Macfarlane, P.W., Sommargren, C., Swiryn, S., Van Hare, G.F. and American Heart Association (2005) AHA scientific statement: Practice standards for electrocardiographic monitoring in hospital settings: An American Heart Association Scientific Statement from the Councils on Cardiovascular Nursing, Clinical Cardiology, and Cardiovascular Disease in the Young: Endorsed by the International Society of Computerized electrocardiology and the American Association of Critical-Care Nurses. Journal of Cardiovascular Nursing, 20, 76-106.

http://dx.doi.org/10.1097/00005082-200503000-00003

[2] Bonow, R.O., Mann, D.L., Zipes, D.P. and Libby, P. (2011) Braunwald's heart disease: A textbook of cardiovascular medicine, 2-volume set: Expert consult premium edition-enhanced online features and print. 9th Edition, Saunders.

[3] Malmivuo, J. and Plonsey, R. (1995) Bioelectromagnetism: principles and applications of bioelectric and biomagnetic fields. Oxford University Press, New York. http://dx.doi.org/10.1093/acprof:oso/9780195058239.001 .0001

[4] Menown, I.B., Mackenzie, G. and Adgey, A.A. (2000) Optimizing the initial 12-lead electrocardiographic diagnosis of acute myocardial infarction. European Heart Journal, 21, 275-283. ttp://dx.doi.org/10.1053/euhj.1999.1748

[5] Brady, W.J., Chan, T.C. and Pollack, M. (2000) Electrocardiographic manifestations: Patterns that confound the EKG diagnosis of acute myocardial infarction-left bundle 
branch block, ventricular paced rhythm, and left ventricular hypertrophy. Journal of Emergency Medicine, 18, 71-78. http://dx.doi.org/10.1016/S0736-4679(99)00178-X

[6] Sovilj, S., Magjarevic, R., Lovell, N.H. and Dokos, S. (2013) A simplified 3D model of whole heart electrical activity and 12-lead ECG generation. Computational and Mathematical Methods in Medicine, 2013, Article ID: 134208.

[7] Keller, D.U.J, Seemann, G., Weiss, D.L., Farina, D., Zehelein, J. and Dossel, O. (2007) Computer based modeling of the congenital long-QT 2 syndrome in the Visible Man torso: From genes to ECG. Proceedings of the 29th Annual International Conference of the IEEE EMBS, Lyon, 23-26 August 2007, 1410-1413.

[8] Boulakia, M., Cazeau, S., Fernández, M.A., Gerbeau, J.-F. and Zemzemi, N. (2010) Mathematical modeling of electrocardiograms: A numerical study. Annals of Biomedical Engineering, 38, 1071-1097.

http://dx.doi.org/10.1007/s10439-009-9873-0

[9] Potse, M., Dubé, B. and Vinet, A. (2009) Cardiac anisotropy in boundary-element models for the electrocardiogram. Medical \& Biological Engineering \& Computing, 47, 719-729.

http://dx.doi.org/10.1007/s11517-009-0472-x

[10] Potse, M., Dube, B. and Gulrajani, R.M. (2003) ECG simulations with realistic human membrane, heart, and torso models. Proceedings of the 25th Annual International Conference of the IEEE EMBS, Cancun, 17-21 September 2003, 70-73.

[11] Lab, M.J. (1996) Mechanoelectric feedback (transduction) in heart: Concepts and implications. Cardiovascular Research, 32, 3-14.

[12] Taggart, P. (1996) Mechano-electric feedback in the human heart. Cardiovascular Research, 32, 38-43.

[13] Taggart, P. and Sutton, P.M. (1999) Cardiac mechanoelectric feedback in man: Clinical relevance. Progress in Biophysics and Molecular Biology, 71, 139-154. http://dx.doi.org/10.1016/S0079-6107(98)00039-X

[14] Kelly, D., Mackenzie, L., Hunter, P., Smaill, B. and Saint, D.A. (2006) Gene expression of stretch-activated channels and mechanoelectric feedback in the heart. Clinical and Experimental Pharmacology and Physiology, 33, 642-648.

http://dx.doi.org/10.1111/j.1440-1681.2006.04392.x

[15] Katz, A. (2010) Physiology of the heart. 5th Edition, Lippincott Williams \& Wilkins, Philadelphia.

[16] Franz, M.R. (1996) Mechano-electrical feedback in ventricular myocardium. Cardiovascular Research, 32, 1524.

[17] Lab, M.J. (1982) Contraction-excitation feedback in myocardium. Physiological basis and clinical relevance. Circulation Research, 50, 757-766. http://dx.doi.org/10.1161/01.RES.50.6.757

[18] Ward, M.-L. and Allen, D.G. (2010) Stretch-activated channels in the heart: Contribution to cardiac performance. In: Kamkin, A. and Kiseleva, I., Ed., Mechanosensitivity of the Heart Mechanosensitivity in Cells and Tissues, Springer, Dordrecht, 141-167.
[19] Youm, J.B., Han, J., Kim, N., Zhang, Y.-H., Kim, E., Leem, C.H., Kim, S.H. and Earm, Y.E. (2005) Role of stretch-activated channels in the heart: Action potential and $\mathrm{Ca}^{2+}$ transients. In: Kamkin, A. and Kiseleva, I., Ed., Mechanosensitivity in Cells and Tissues, Academia, Moscow.

[20] Belus, A. and White, E. (2003) Streptomycin and intracellular calcium modulate the response of single guineapig ventricular myocytes to axial stretch. The Journal of Physiology, 546, 501-509. http://dx.doi.org/10.1113/jphysiol.2002.027573

[21] Zeng, T., Bett, G.C. and Sachs, F. (2000) Stretch-activated whole cell currents in adult rat cardiac myocytes. American Journal of Physiology. Heart and Circulatory Physiology, 278, H548-H557.

[22] Dean, J.W. and Lab, M.J. (1989) Effect of changes in load on monophasic action potential and segment length of pig heart in situ. Cardiovascular Research, 23, 887896. http://dx.doi.org/10.1093/cvr/23.10.887

[23] Franz, M.R., Burkhoff, D., Yue, D.T. and Sagawa, K. (1989) Mechanically induced action potential changes and arrhythmia in isolated and in situ canine hearts. Cardiovascular Research, 23, 213-223. http://dx.doi.org/10.1093/cvr/23.3.213

[24] Hansen, D.E. (1993) Mechanoelectrical feedback effects of altering preload, afterload, and ventricular shortening. American Journal of Physiology, 264, H423-H432.

[25] O’Hara, T., Virág, L., Varró, A. and Rudy, Y. (2011) Simulation of the undiseased human cardiac ventricular action potential: Model formulation and experimental validation. PLOS Computational Biology, 7, Article ID: e1002061. http://dx.doi.org/10.1371/journal.pcbi.1002061

[26] Rice, J.J., Wang, F., Bers, D.M. and de Tombe, P.P. (2008) Approximate model of cooperative activation and crossbridge cycling in cardiac muscle using ordinary differential equations. Biophysical Journal, 95, 2368-2390. http://dx.doi.org/10.1529/biophysj.107.119487

[27] Adeniran, I., Hancox, J. and Zhang, H. (2013) In silico investigation of the short QT syndrome, using human ventricle models incorporating electromechanical coupling. Front Physiology, 4, 166.

[28] Panfilov, A.V., Keldermann, R.H. and Nash, M.P. (2005) Self-organized pacemakers in a coupled reaction-diffusion-mechanics system. Physical Review Letters, 95, Article ID: 258104.

http://dx.doi.org/10.1103/PhysRevLett.95.258104

[29] Lunze, K., Stålhand, J. and Leonhardt, S. (2010) Modeling of stretch-activated sarcolemmal channels in smooth muscle cells. Proceedings of the World Congress on $\mathrm{Me}$ dical Physics and Biomedical Engineering IFMBE, Munich, 7-12 September 2009, 740-743.

[30] Kuijpers, N.H.L. (2008) Cardiac electrophysiology and mechanoelectric feedback. Ph.D. Thesis, Eindhoven University of Technology, Eindhoven.

[31] Kohl, P. and Sachs, F. (2001) Mechanoelectric feedback in cardiac cells. Philosophical Transactions of the Royal Society A, 359, 1173-1185.

http://dx.doi.org/10.1098/rsta.2001.0824 
[32] Trayanova, N., Li, W., Eason, J. and Kohl, P. (2004) Effect of stretch-activated channels on defibrillation efficacy. Heart Rhythm, 1, 67-77. http://dx.doi.org/10.1016/j.hrthm.2004.01.002

[33] Kohl, P., Hunter, P. and Noble, D. (1999) Stretch-induced changes in heart rate and rhythm: Clinical observations, experiments and mathematical models. Progress in Biophysics and Molecular Biology, 71, 91-138. http://dx.doi.org/10.1016/S0079-6107(98)00038-8

[34] Zabel, M., Koller, B.S., Sachs, F. and Franz, M.R. (1996) Stretch-induced voltage changes in the isolated beating heart: importance of the timing of stretch and implications for stretch-activated ion channels. Cardiovascular Research, 32, 120-130.

[35] Kamkin, A., Kiseleva, I. and Isenberg, G. (2000) Stretchactivated currents in ventricular myocytes: Amplitude and arrhythmogenic effects increase with hypertrophy. Cardiovascular Research, 48, 409-420. http://dx.doi.org/10.1016/S0008-6363(00)00208-X

[36] Marsden, J.E. and Hughes, T.J.R. (1994) Mathematical foundations of elasticity. Dover Publications, New York.

[37] Holzapfel, G.A. (2000) Nonlinear solid mechanics: A continuum approach for engineering. John Wiley \& Sons Ltd., Chichester.

[38] Pathmanathan, P. and Whiteley, J.P. (2009) A numerical method for cardiac mechanoelectric simulations. Annals of Biomedical Engineering, 37, 860-873. http://dx.doi.org/10.1007/s10439-009-9663-8

[39] Costa, K.D., Holmes, J.W. and Mcculloch, A.D. (2001) Modelling cardiac mechanical properties in three dimensions. Philosophical Transactions of the Royal Society A, 359, 1233-1250. http://dx.doi.org/10.1098/rsta.2001.0828

[40] Hunter, P.J., Nash, M.P. and Sands, G.B. (1997) Computational mechanics of the heart. In: Panfilov, A.V. and Holden, A.V., Eds., Computational Biology of the Heart. Wiley, West Sussex, 345-407.

[41] Niederer, S.A. and Smith, N.P. (2008) An improved numerical method for strong coupling of excitation and contraction models in the heart. Progress in Biophysics and Molecular Biology, 96, 90-111. http://dx.doi.org/10.1016/j.pbiomolbio.2007.08.001

[42] Whiteley, J.P., Bishop, M.J. and Gavaghan, D.J. (2007) Soft tissue modelling of cardiac fibres for use in coupled mechano-electric simulations. Bulletin of Mathematical Biology, 69, 2199-2225. http://dx.doi.org/10.1007/s11538-007-9213-1

[43] Bonet, J. and Wood, R.D. (2008) Nonlinear continuum mechanics for finite element analysis. 2nd Edition, Cambridge University Press, Cambridge. http://dx.doi.org/10.1017/CBO9780511755446

[44] Le Tallec, P. (1994) Numerical methods for nonlinear three-dimensional elasticity. In: Lions, J.L. and Ciarlet, P.G., Eds., Handbook of Numerical Analysis; Vol.3, Techniques of Scientific Computing (part 1); Numerical Methods for Solids (part 1); Solution of Equations in R(n) (part 2), North-Holland, London.

[45] Keldermann, R.H., Nash, M.P. and Panfilov, A.V (2009) Modeling cardiac mechano-electrical feedback using re- action-diffusion-mechanics systems. Physica D: Nonlinear Phenomena, 238, 1000-1007.

http://dx.doi.org/10.1016/j.physd.2008.08.017

[46] Auricchio, F., Beirão da Veiga, L., Lovadina, C. and Reali, A. (2010) The importance of the exact satisfaction of the incompressibility constraint in nonlinear elasticity: Mixed FEMs versus NURBS-based approximations. Computer Methods in Applied Mechanics and Engineering, 199, 314-323. http://dx.doi.org/10.1016/j.cma.2008.06.004

[47] Braess, D. and Ming, P. (2005) A finite element method for nearly incompressible elasticity problems. Math Comp, 74, 25-52.

http://dx.doi.org/10.1090/S0025-5718-04-01662-X

[48] Braess, D. (2007) Finite elements: Theory, fast solvers, and applications in solid mechanics. 3rd Edition, Cambridge University Press, Cambridge. http://dx.doi.org/10.1017/CBO9780511618635

[49] Brenner, S.C. and Scott, R. (2010) The mathematical theory of finite element methods. 3rd Edition, Springer, New York.

[50] Seemann, G., Keller, D.U.J., Weiss, D.L. and Dössel, O. (2006) Modeling human ventricular geometry and fiber orientation based on diffusion tensor MRI. Computers in Cardiology, 33, 801-804.

[51] Legrice, I.J., Hunter, P.J. and Smaill, B.H. (1997) Laminar structure of the heart: A mathematical model. The American Journal of Physiology, 272, H2466-H2476.

[52] Lilli, A., Baratto, M.T., Meglio, J.D., Chioccioli, M., Magnacca, M., Talini, E., Canale, M.L., Poddighe, R., Comella, A. and Casolo, G. (2013) Left ventricular rotation and twist assessed by four-dimensional speckle tracking echocardiography in healthy subjects and pathological remodeling: A single center experience. Echocardiography, 30, 171-179.

http://dx.doi.org/10.1111/echo.12026

[53] Lorenz, C.H., Pastorek, J.S. and Bundy, J.M. (2000) Delineation of normal human left ventricular twist throughout systole by tagged cine magnetic resonance imaging. Journal of Cardiovascular Magnetic Resonance, 2, 97108. http://dx.doi.org/10.3109/10976640009148678

[54] Tseng, W-Y.I., Reese, T.G., Weisskoff, R.M., Brady, T.J. and Wedeen, V.J. (2000) Myocardial fiber shortening in humans: Initial results of MR imaging. Radiology, 216, 128-139.

http://dx.doi.org/10.1148/radiology.216.1.r00jn39128

[55] MacGowan, G.A., Shapiro, E.P., Azhari, H., Siu, C.O., Hees, P.S., Hutchins, G.M., Weiss, J.L. and Rademakers, F.E. (1997) Noninvasive measurement of shortening in the fiber and cross-fiber directions in the normal human left ventricle and in idiopathic dilated cardiomyopathy. Circulation, 96, 535-541. http://dx.doi.org/10.1161/01.CIR.96.2.535

[56] Coppola, B.A. and Omens, J.H. (2008) Role of tissue structure on ventricular wall mechanics. MCB Molecular and Cellular Biomechanics, 5, 183-196.

[57] Cheng, A., Nguyen, T.C., Malinowski, M., Daughters, G.T., Miller, D.C. and Ingels Jr., N.B. (2008) Heterogeneity of left ventricular wall thickening mechanisms. Cir- 
culation, 118, 713-721.

http://dx.doi.org/10.1161/CIRCULATIONAHA.107.7446 $\underline{23}$

[58] Bogaert, J. and Rademakers, F.E. (2001) Regional nonuniformity of normal adult human left ventricle. American Journal of Physiology. Heart and Circulatory Physiology, 280, H610-H620.

[59] Guccione, J.M., McCulloch, A.D. and Waldman, L.K. (1991) Passive material properties of intact ventricular myocardium determined from a cylindrical model. Journal of Biomechanical Engineering, 113, 42-55. http://dx.doi.org/10.1115/1.2894084

[60] Land, S., Niederer, S.A. and Smith, N.P. (2012) Efficient computational methods for strongly coupled cardiac electromechanics. IEEE Transactions on Biomedical Engineering, 59, 1219-1228. http://dx.doi.org/10.1109/TBME.2011.2112359

[61] Colli Franzone, P., Pavarino, L.F. and Taccardi, B. (2005) Simulating patterns of excitation, repolarization and action potential duration with cardiac bidomain and monodomain models. Mathematical Biosciences, 197, 35-66. http://dx.doi.org/10.1016/j.mbs.2005.04.003

[62] Potse, M., Dubé, B., Richer, J., Vinet, A. and Gulrajani, R.M. (2006) A comparison of monodomain and bidomain reaction-diffusion models for action potential propagation in the human heart. IEEE Transactions on Biomedical Engineering, 53, 2425-2435. http://dx.doi.org/10.1109/TBME.2006.880875

[63] Keener, J. and Sneyd, J. (2008) Mathematical physiology: II: Systems physiology. 2nd Edition, Springer, New York.

[64] Nash, M.P. and Panfilov, A.V. (2004) Electromechanical model of excitable tissue to study reentrant cardiac arrhythmias. Progress in Biophysics and Molecular Biology, 85, 501-522. http://dx.doi.org/10.1016/j.pbiomolbio.2004.01.016

[65] Taggart, P., Sutton, P.M., Opthof, T., Coronel, R., Trimlett, R., Pugsley, W. and Kallis, P. (2000) Inhomogeneous transmural conduction during early ischaemia in patients with coronary artery disease. Journal of Molecular and Cellular Cardiology, 32, 621-630. http://dx.doi.org/10.1006/jmcc.2000.1105

[66] Plonsey, R. and Barr, R.C. (2007) Bioelectricity: A quantitative approach. 3rd Edition, Springer, New York.

[67] Drouin, E., Charpentier, F., Gauthier, C., Laurent, K. and Le Marec, H. (1995) Electrophysiologic characteristics of cells spanning the left ventricular wall of human heart: Evidence for presence of M cells. Journal of the American College of Cardiology, 26, 185-192. http://dx.doi.org/10.1016/0735-1097(95)00167-X

[68] Keller, D.U.J., Kalayciyan, R., Dössel, O. and Seemann, G. (2009) Fast creation of endocardial stimulation profiles for the realistic simulation of body surface ECGs. Proceedings of the World Congress on Medical Physics and Biomedical Engineering IFMBE, Munich, 7-12 September 2009, 145-148.

[69] Sundnes, J., Lines, G.T. and Tveito, A. (2005) An operator splitting method for solving the bidomain equations coupled to a volume conductor model for the torso. $\mathrm{Ma}$ thematical Biosciences, 194, 233-248. http://dx.doi.org/10.1016/j.mbs.2005.01.001

[70] Burnett, D.S. (1987) Finite element analysis: From concepts to applications. Addison Wesley, Massachusetts.

[71] Ern, A. and Guermond, J.L. (2010) Theory and practice of finite elements. Springer, New York.

[72] Rush, S. and Larsen, H. (1978) A practical algorithm for solving dynamic membrane equations. IEEE Transactions on Biomedical Engineering, 25, 389-392. http://dx.doi.org/10.1109/TBME.1978.326270

[73] Cohen, S. and Hindmarsh, A.C. (1996) CVODE, A stiff/ nonstiff ode solver in C. In: Holmes, L.M. Ed., Computers in Physics, American Institute of Physics Inc, New York, 138-143

[74] Hindmarsh, A.C., Brown, P.N., Grant, K.E., Lee, S.L., Serban, R., Shumaker, D.E. and Woodward, C.S. (2005) SUNDIALS: Suite of nonlinear and differential/algebraic equation solvers. ACM Transactions on Mathematical Software, 31, 363-396.

http://dx.doi.org/10.1145/1089014.1089020

[75] Logg, A., Mardal, K.A. and Wells, G. (2012) Automated solution of differential equations by the finite element method: The FEniCS book. Springer, New York.

http://dx.doi.org/10.1007/978-3-642-23099-8

[76] Chamberland, E., Fortin, A. and Fortin, M. (2010) Comparison of the performance of some finite element discretizations for large deformation elasticity problems. Computers \& Structures, 88, 664-673. http://dx.doi.org/10.1016/j.compstruc.2010.02.007

[77] Haga, J.B., Osnes, H. and Langtangen, H.P. (2012) On the causes of pressure oscillations in low-permeable and low-compressible porous media. International Journal for Numerical and Analytical Methods in Geomechanics, 36, 1507-1522. http://dx.doi.org/10.1002/nag.1062

[78] Hughes, T.J.R. (2000) The finite element method: Linear static and dynamic finite element analysis. Dover Publications, Dover.

[79] McIntosh, M.A., Cobbe, S.M. and Smith, G.L. (2000) Heterogeneous changes in action potential and intracellular $\mathrm{Ca}^{2+}$ in left ventricular myocyte sub-types from rabbits with heart failure. Cardiovascular Research, 45, 397-409. http://dx.doi.org/10.1016/S0008-6363(99)00360-0

[80] Woodworth, R.S. (1902) Maximal contraction, 'staircase' contraction, refractory period, and compensatory pause, of the heart. American Journal of Physiology, 8, 213-249.

[81] Mulieri, L.A., Hasenfuss, G., Leavitt, B., Allen, P.D. and Alpert, N.R. (1992) Altered myocardial force-frequency relation in human heart failure. Circulation, 85, 1743-1750. http://dx.doi.org/10.1161/01.CIR.85.5.1743

[82] Lakatta, E.G. (2004) Beyond Bowditch: The convergence of cardiac chronotropy and inotropy. Cell Calcium, 35, 629-642. http://dx.doi.org/10.1016/j.ceca.2004.01.017

[83] Boland, J. and Troquet, J. (1980) Intracellular action potential changes induced in both ventricles of the rat by an acute right ventricular pressure overload. Cardiovascular Research, 14, 735-740. http://dx.doi.org/10.1093/cvr/14.12.735

[84] Franz, M.R., Cima, R., Wang, D., Profitt, D. and Kurz, R. (19920 Electrophysiological effects of myocardial stretch 
and mechanical determinants of stretch-activated arrhythmias. Circulation, 86, 968-978.

http://dx.doi.org/10.1161/01.CIR.86.3.968

[85] Calkins, H., El-Atassi, R., Kalbfleisch, S., Langberg, J. and Morady, F. (1992) Effects of an acute increase in atrial pressure on atrial refractoriness in humans. Pacing and Clinical Electrophysiology, 15, 1674-1680. http://dx.doi.org/10.1111/j.1540-8159.1992.tb02954.x

[86] Alvarez, B.V., Pérez, N.G., Ennis, I.L., Camilión de Hurtado, M.C. and Cingolani, H.E. (1999) Mechanisms underlying the increase in force and $\mathrm{Ca}^{2+}$ transient that follow stretch of cardiac muscle: A possible explanation of the Anrep effect. Circulation Research, 85, 716-722. http://dx.doi.org/10.1161/01.RES.85.8.716

[87] Baartscheer, A., Schumacher, C.A., van Borren M.M.G.J, Belterman, C.N.W, Coronel, R. and Fiolet, J.W.T. (2003) Increased $\mathrm{Na}^{+} / \mathrm{H}^{+}$-exchange activity is the cause of increased $[\mathrm{Na}+] \mathrm{i}$ and underlies disturbed calcium handling in the rabbit pressure and volume overload heart failure model. Cardiovascular Research, 57, 1015-1024. http://dx.doi.org/10.1016/S0008-6363(02)00809-X

[88] Calaghan, S.C., Belus, A. and White, E. (2003) Do stretchinduced changes in intracellular calcium modify the electrical activity of cardiac muscle? Progress in Biophysics and Molecular Biology, 82, 81-95. http://dx.doi.org/10.1016/S0079-6107(03)00007-5

[89] Calaghan, S.C. and White, E. (1999) The role of calcium in the response of cardiac muscle to stretch. Progress in Biophysics and Molecular Biology, 71, 59-90. http://dx.doi.org/10.1016/S0079-6107(98)00037-6

[90] Barcenas-Ruiz, L., Beuckelmann, D.J. and Wier, W.G. (1987) Sodium-calcium exchange in heart: Membrane currents and changes in [Ca2+]i. Science, 238, 1720-1722. http://dx.doi.org/10.1126/science. 3686010

[91] Hall, J.E. and Guyton, A.C. (2010) Textbook of medical physiology. 12th Edition, Saunders, Philadelphia.

[92] Rhoades, R. and Bell, D.R. (2013) Medical physiology: principles for clinical medicine. 4th Edition, Wolters Kluwer Health/Lippincott Williams \& Wilkins, Philadelphia.

[93] DiMino, T.L., Ivanov, A., Burke, J.F. and Kowey, P.R. (2006) Electrocardiography. In: Rosendorff, C., Ed., Essential Cardiology: Principles and Practice, Humana Press, Clifton, 117-138. http://dx.doi.org/10.1007/978-1-59259-918-9 8

[94] Klabunde, R.E. (2012) Cardiovascular physiology concepts. 2nd Edition, Lippincott Williams \& Wilkins/Wolters Kluwer, Philadelphia.

[95] Bett, G.C. and Sachs, F. (1997) Cardiac mechanosensitivity and stretch-activated ion channels. Trends in Cardiovascular Medicine, 7, 4-8. http://dx.doi.org/10.1016/S1050-1738(96)00119-3

[96] Sengupta, P.P., Tajik, A.J., Chandrasekaran, K. and Khandheria, B.K. (2008) Twist mechanics of the left ventricle: Principles and application. JACC: Cardiovascular Imaging, 1, 366-376. http://dx.doi.org/10.1016/j.jcmg.2008.02.006
[97] Sengupta, P.P., Khandheria, B.K. and Narula, J. (2008) Twist and untwist mechanics of the left ventricle. Heart Failure Clinics, 4, 315-324. http://dx.doi.org/10.1016/i.hfc.2008.03.001

[98] Hodt, A., Stugaard, M., Hisdal, J., Stranden, E., Atar, D. and Steine, K. (2012) Regional LV deformation in healthy individuals during isovolumetric contraction and ejection phases assessed by 2D speckle tracking echocardiography. Clinical Physiology and Functional Imaging, 32, 372-379. http://dx.doi.org/10.1111/j.1475-097X.2012.01139.x

[99] Lionel, H.O. (2006) Ventricular Function. In: Rosendorff, C., Ed., Essential Cardiology: Principles and Practice, Human Press, New Jersey, 37-54.

[100] Wei, Q., Liu, F., Appleton, B., Xia, L., Liu, N., Wilson, S., Riley, R., Strugnel, W., Slaughter, R., Denman, R. and Crozier, S. (2006) Effect of cardiac motion on body surface electrocardiographic potentials: An MRI-based simulation study. Physics in Medicine and Biology, 51, 34053418. http://dx.doi.org/10.1088/0031-9155/51/14/009

[101] Xia, L., Huo, M., Wei, Q., Liu, F. and Crozier, S. (2005) Analysis of cardiac ventricular wall motion based on a three-dimensional electromechanical biventricular model. Physics in Medicine and Biology, 50, 1901-1917. http://dx.doi.org/10.1088/0031-9155/50/8/018

[102] Smith, N.P., Buist, M.L. and Pullan, A.J. (2003) Altered $\mathrm{T}$ wave dynamics in a contracting cardiac model. Journal of Cardiovascular Electrophysiology, 14, S203-S209. http://dx.doi.org/10.1046/j.1540.8167.90312.x

[103] Mao, H.D., Wang, L.W., Wong, C.L., Liu, H.F. and Shi, P.C. (2011) A coupled heart-torso framework for cardiac electrocardiographic simulation. Computing in Cardiology, 38, 225-228.

[104] Horner, S.M., Dick, D.J., Murphy, C.F. and Lab, M.J. (1996) Cycle length dependence of the electrophysiological effects of increased load on the myocardium. Circulation, 94, 1131-1136. http://dx.doi.org/10.1161/01.CIR.94.5.1131

[105] Sung, D., Mills, R.W., Schettler, J., Narayan, S.M., Omens, J.H. and McCulloch, A.D. (2003) Ventricular filling slows epicardial conduction and increases action potential duration in an optical mapping study of the isolated rabbit heart. Journal of Cardiovascular Electrophysiology, 14, 739-749. http://dx.doi.org/10.1046/j.1540-8167.2003.03072.x

[106] Kohl, P., Camelliti, P., Burton, F.L. and Smith, G.L. (2005) Electrical coupling of fibroblasts and myocytes: Relevance for cardiac propagation. Journal of Electrocardiology, 38, 45-50. http://dx.doi.org/10.1016/j.jelectrocard.2005.06.096

[107] Thompson, S.A., Copeland, C.R., Reich, D.H. and Tung, L. (2011) Mechanical coupling between myofibroblasts and cardiomyocytes slows electric conduction in fibrotic cell monolayers. Circulation, 123, 2083-2093. http://dx.doi.org/10.1161/CIRCULATIONAHA.110.0150 57 